\title{
Sexuality and Women's Sexual Rights in the Gambia
}

\section{Isatou Touray}

\section{Introduction}

Why do sexual rights and women's sexual rights in particular attract such controversy, especially in the African context? In all societies, women's sexuality is socially and politically constructed, and in many it is also shrouded in secrecy, not subject to the light of public debate. In the Gambia, these two facts combine to cast the notion of sexual rights as a foreign import, designed to undermine culture, tradition and dignity.

Making this landscape more slippery, many African feminists would agree that 'international' prescriptions of what is to be done to work on sexual rights and issues around them - which assume normative power in the contemporary political scene - do not often translate easily into the lived realities of African women. The meanings of sexual rights and issues around sexuality need to be grounded in the real issues of different contexts. This article seeks to contribute to this project by taking as its focus some issues concerning sexual rights which have clear manifestations among women in Gambian society, and investigating the details of this resonance by describing how sexual rights - or their denial - are experienced by Gambian women.

It further argues, however, that key issues concerning sexual rights are not the same for all Gambian women, nor do they remain the same over one woman's life cycle. Key sexual rights issues are not likely to be the same for a young urban woman and a middle-aged rural woman. A nuanced analytical approach is needed, grounded in the realities of different women's lives, and which foregrounds the fact that not all women are the same.

Sexual rights issues that have cultural resonance in the Gambia include polygamy, early marriage, sexual abuse, female genital mutilation, marital/statutory rape, forced retirement by spouse from sex due to the menopause, the trafficking of women and lesbianism. The first section of this article describes the socioreligious context which frames struggles over sexual rights, commenting that this context is neither homogenous nor fixed, and does offer spaces for contest which are being taken up by African feminists in many ways. The following sections then look at each issue in turn, bringing out the ways in which sexuality is constructed and experienced at different points in the lives of different groups of women. This article and the perspectives it offers are influenced by the grassroots activism I engage in with my colleagues in the Gambia, working with poor and powerless women and girl children whose roles and positions profoundly circumscribe their sexuality and sexual rights. I draw, in what follows, on testimony from some of these women, who narrated their experiences in workshops organised by my organisation, GAMCOTRAP (Gambian Committee on Traditional Practices).

\section{The socioreligious framework: discourses of sexuality}

Islam has been and remains influential in constructing lived experiences of sexuality in the Gambia. Muslim personal status law regulates issues of inheritance, marriage, custody, divorce, widowhood, sex and the sexual autonomy of Muslim women. Current constructions of 'tradition' in Islam cast anything related to sex and sexuality within the framework of marriage in all its modalities, and anything related to sexual desire and pleasure in the framework of heterosexual relationships as the normative practice.

Yet historically, different schools of thought in Islam have offered different constructions of women's sexuality. Classical and medieval Islamic scholarship, for example the works of Al Ghazali and of the Sufis, have emphasised the erotic dimensions of sexuality in Islam. Prevailing contemporary interpretations have 
their roots in an era in which modern Muslim society was becoming more politicised and restricted, just as contemporary Western notions of sexuality have their roots in a Victorian culture which strove to organise sex and sexuality within the framework of the church. Post-modern discourses of sexuality have challenged some of the restrictive interpretations of Islam, to reclaim some of the practices of the past. Muslim feminists and progressivists involved in ljthihad (the process of extracting rules) have undertaken a process of analysing sexuality, particularly women's sexuality. In so doing they have created spaces in which women of all kinds are beginning both to question the monolithic appearance of conservative interpretations, and to investigate the meaning of women's sexual rights in different contexts in Africa (llkkaracan 2002; Imam 2005; GAMCOTRAP 2003).

\section{Constructions of sexuality; denials of sexual rights}

The conservative Muslim socioreligious framework is a powerful factor in constructing notions of sexuality, and hence sexual rights in the Gambia, but it is not the only one. Notions of tradition, culture, family, community and economic expedience all come into play. The following sections describe some of the ways in which sexuality is constructed; the issues through which it is experienced; and the consequences of sexual rights abuse at different moments in women's lives.

\subsection{Being born a girl}

A child's sex at birth strongly influences the landscape of sexual rights for both the child itself, and for its mother. While girl children suffer early discrimination in terms of education and socialisation/sexualisation, their mothers' sexual options are also circumscribed by the sex of their babies.

While both girl and boy children are welcome in Gambian households, there is a strong desire to have more boys than girls. Women are known to undertake 'extra' pregnancies in the hope of fulfilling this desire. Failure to fulfil it brings the risk of marital neglect and domestic abuse: Sarjo explains her plight:

I am no longer the favourite wife because I have only girls and my sisters-in-law are always reminding me that I was brought in the compound to give them an heir. I have to put up with all the verbal abuses I get from my husband, mother-in-law and sisters-in-law. I wish I could give myself a baby boy.

For the child, religious and cultural conceptions of the boy child as the (future) head of household who will continue the family line affect children of both sexes. Boy children are socially and materially privileged, while for girl children discrimination has both psychological and economic consequences. Many internalise their disprivilege, affecting their sense of dignity and individual integrity and hence their sexuality throughout their lives. Meanwhile, material opportunities such as education, skills and other resources that are available to the household are mostly withheld from them, in favour of boys.

Fatou has the following to say:

My husband is pumping all his money to educate Modou to enable him go abroad so that he will provide for us security, since he is the eldest male. After him the younger boys namely Abdou, Marlick and Alieu will follow. Kumba will marry and stay in another homestead and be looked after.

Withholding education, in the interests of preparing girls like Kumba for marriage is extremely common in rural areas, particularly in the secondary education stages. This practice has an insidious effect on sexual rights as without education, it is even more difficult to resist sexual and other abuse.

\subsection{Female genital mutilation (FGM)}

Statistics from different sources in the Gambia have shown that over 80-90 per cent of Gambian women are circumcised. $A$ recent study by the Medical Research Council (MRC) in the Gambia have corroborated this with a prevalence rate of 97 per cent among those examined. The study has shown that a total of 1,157 women consented to gynaecological examination and 58 per cent had signs of genital cutting. The study also revealed that there was a high level of agreement (97 per cent) between reported circumcision status and that found on examination (Morison et al. 2001: 643). The children of practising ethnic groups are particularly vulnerable.

The practice of FGM takes two forms: removal of only the clitoris (clitoridectomy) or including also removal of the labia minora (excision). Gambian law 
protects girls from neither, and the political will to stop it is ambivalent on the grounds that the practice is an important symbol of 'culture'. While some individual families are responding to the call to stop the practice, most are yet to pay heed, and pressures from the extended family often outweigh the efforts of nuclear families to stop FGM. Gambia has witnessed two FGM court cases recently, one of which was thrown out due to the lack of any law protecting those who do not want to circumcise their children.

Nevertheless, there have been some ways forward. Scientific evidence on the health effects of FGM specifically in the Gambia can strengthen the hand of women's rights organisations like GAMCOTRAP in advocating against it and who often face demands for nation-specific evidence. The recent MRC study revealed that women who had undergone 'Female Genital Cutting' had a significantly higher prevalence of bacterial vaginosis, and a substantially higher prevalence of herpes simplex 2 (HSV2) - suggesting that 'cut' women (or women subjected to the practice of genital mutilation) may be at increased risk of HIV infection (Morison et al. 2001: 643). However, the study remained ambivalent on the relationship between FGM and long-term morbidity and more research is urgently needed, especially on the differential implications of each type of FGM.

However, studies such as these tend to lose the insights available to a rights approach. Gathering culturally responsive scientific evidence regarding FGM in the Gambia requires a cultural sensitivity not available to the MRC if its researchers do not include doctors and nurses who are rooted in the culture under investigation. Given the culture of silence around sexuality in general and FGM in particular, it is difficult to see how such studies, conducted as they are in hospitals, can capture all the relevant evidence around women's sexual health. They are certainly unlikely to reveal its erotic dimensions.

\section{GAMCOTRAP has over the years collected} testimonies and stories from women and men who have revealed some of the effects of FGM from a sexual perspective. Many of our respondents have reported experiencing dry sex and painful sexual intercourse. Whether the dry or painful sex is associated with FGM or not needs to be further investigated. The respondents also revealed that foreplay is not a practice they engage in. The rights- based approach offers a way of taking these issues forward; of articulating FGM's role in denying sexual fulfilment.

GAMCOTRAP has also worked at legal levels to address FGM. During the recent court cases, the organisation started working closely with those involved and began to generate constructive dialogue between circumcisers, traditional birth attendants and the organisation on how they can work together to end FGM.

\subsection{The 'reproductive years' Early marriage}

There is no legal minimum age for marriage under customary law, and what constitutes 'youth' ranges from 13-30 years in different legal contexts, making young girls directly vulnerable to abuse. Many girls are still subjected to early marriage, affecting their chances to fulfil their life opportunities and to develop their individuality.

The protagonists of early marriage lure parents into withdrawing girls from school for marriage, claiming it is the most honourable and dignifying decision. The fear of unwanted pregnancy is also a frequent argument for early marriage, although male early sexual indulgence is rarely questioned. The trends observed in our community outreach activities suggest most often that elderly men are involved in the practice of early marriage and are not interested in the girl's education. Mothers, on the other hand, seem to be responding to the call for increasing girl's education and are taking more responsibility for ensuring that their daughters continue in school.

Early marriage may be 'honourable' but it does not guarantee that the marriage will last forever. Divorce in the Gambian context among Muslims is as easy as changing a garment. The laws protecting the rights of women in divorce are rarely enforced. Girls, withdrawn from school to marry at an early age, sometimes suffer the bangs of divorce on very flimsy grounds. The prevalence of early marriage has also resulted in men abandoning older wives for younger ones, who will also be abandoned later for a much younger wife, and hence the vicious cycle of abuse continues.

Early marriage also brings its own problems. Young girls - because they are young - are unable to negotiate sex or decide the number of children they 
would like to have. Lack of education also contributes to the vicious cycle of ignorance and lack of knowledge about one's rights. Marriage to elderly men can be sexually frustrating for young girls, who may then seek risky alternative solutions. As Fatou explains:

When these girls are withdrawn from school and married to these elderly men they end up looking for stronger men resulting in unwanted pregnancies. Sometimes they are divorced and left with having to face the responsibility of fending for their young babies.

\section{Polygamy/polygyny}

According to Muslim scholars, polygamy is a privilege enshrined in the Koran for men who are qualified to practice it, with very strong restrictions and conditionalities, which make it difficult for most men to qualify. The practice is highly restricted in many Muslim states where the Koranical dictates and principles of polygamy, which protect the rights of women and the children of polygamous marriages, are recognised. The ability to treat co-wives justly is a strict precondition to the practice, following the verses in the Koran:

... marry women of your choice, two, three or four; but if you feel you may not be able to deal justly (with them), then only one ... that is nearer to prevent you from doing injustice.

... you will never be able to do perfect justice between wives even if it is your ardent desire. (Koran, Ch. 4: 129)

However, the right to have several wives is strongly claimed by Gambian men, irrespective of one's social background or ability to treat them with 'perfect justice'. Accepted opinion among men is simply that 'Islam gives me the right to keep up to four wives' (GAMCOTRAP 2003: 58). Religious discourses around polygyny emphasise the practice as a divine right for men, with short shrift to the preconditions which are supposed to govern it. Women rarely get to know of these preconditions.

Women enter polygynous marriages for a variety of reasons including fear of being unmarried, avoiding social stigma in a society where marriage is the norm, and fear of having children out of wedlock. Women's sexuality has been constructed so that notions of an ideal woman - or even a minimally socially acceptable woman - serve the interests of men. Penda reveals how these notions have the power to push women into marriage even in the absence of economic or emotional need:

I don't need a man to take care of me because I am employed and can provide all I need for myself. Being an educated woman I am finding it difficult to find a husband to settle with. I kept on asking myself whether I need a husband to self actualise. The answer kept on coming 'No'. But I don't know if I decide to have a child out of wedlock how my family will see it. I only need a child and that is why I am going into this mess.

Similarly, women who marry as first wives and subsequently find themselves in polygynous arrangements, choose to remain because they see men's right to plural wives as divinely bestowed, and in order to avoid compromising the interests of the children. Penda lamented:

I am in this situation because it is my husband's right to get more than one wife. Many women will not get married if men marry only one wife. I know that he cannot afford to give us all what we need, and sometimes we had to fend for ourselves to feed him and the children. It is our faith.

Penda's story reflects a common situation among both rural and urban women in the Gambia.

Polygynous marriages have consequences both for women's sexual rights and for their economic security. Earlier wives often become sexually, emotionally and economically neglected. Aminata said:

I wish that God had come down to see what is happening to us in such a relationship, I am denied sex for the past one year because my husband has a new and younger wife who he spends most of the time with. When I complain he tells me she needs more attention, I am starving and I cannot disclose this to my family. My children are young and I cannot work out of the marriage because it is his right.

Sexual rights in a polgygynous household are greatly determined by the male spouse and women have to 
either negotiate or relinquish their rights when they are violated. It is considered abnormal for women to demand sex from their spouse. Our outreach activities have revealed that many women are sexually deprived, particularly those approaching the menopause or who have attained menopause. In the focus group discussions, all the women came to a consensus that reaching menopause does not affect their sexual ability. Fatou explained that when it was her turn to sleep with her husband he neglected her. In the evening, she saw Modou (her husband) enter Haddy's (the younger wife's) room and she never saw him. Fatou, like many women in similar situations, cannot explain or complain about how she feels because it is taboo for women to admit to being sexually starved a taboo which patently does not apply to men.

The status of children born of the same man and different mothers in polygynous settings is often dependent on the 'status' of their mother in relation to other household members, and the mother's sexual status with regard to the husband is a key determinant of this. Responsibility for children is to a great extent matri-focal with the result that polygynous settings are increasingly characterised by several hearth-holds headed by women within a patriarchal household.

A rights approach can be useful in this situation of normative polygyny, whose perpetuation is often blamed on the women who undertake polygynous marriage. If women understand their social, sexual and indeed religious rights, they are in a much better position to make an informed choice and to negotiate that choice.

\section{Sexual abuse}

Sexual abuse includes rape, assault, molestation, sexual harassment and incest. Abuse is perpetrated by a person who is perceived to hold power over another and occurs in the home, at school, at work, or in a public place. The perpetrators can be family members, supervisors, teachers, community leaders or strangers. Since sexual abuse is an exploitation of power, young people - particularly girls - are especially at risk, and violations can have lasting consequences for their sexual and reproductive health and rights. Sexual abuse also has implications for women's and girls' dignity and integrity.

In the Gambian context, some of the above are simply not acknowledged as sexual abuse. For example assault, molestation and harassment are sometimes regarded as normal in the context of marriage. In Muslim jurisprudence, there is some degree of sanction for them within a marital relationship (Imam 2005; GAMCOTRAP 2003). This has been the arena of contestation between feminist academics and conservative Muslim scholars.

Victims of sexual abuse cannot negotiate sex because they are in positions of powerlessness. The results of this powerlessness can be unwanted pregnancies, sexually transmitted infections, physical injury and trauma. Studies also show that young people who have been sexually abused are more likely to engage in high-risk sexual behaviour than are those who have not been abused. At the same time, stigma attached to victims of rape prevents people from reporting it.

Rape happens almost every day without being reported. Where it is reported, families rarely follow the process through because of the stigma associated with rape and because the legal process is long and difficult. Where sexual abuse is traced to very close family members, the issue is very rarely brought to the public arena. Close family members see it as a source of shame, adopting a culture of silence which perpetuates the practice. Awa narrated:

I don't want to name names since we are at a workshop situation, but the issues we are discussing here are happening everyday, and the culprits are very close relatives and living in the community. We never want to reveal them but they are affecting our lives.

\section{Marital rape}

Marital rape, also referred to as statutory rape in the legal lexicon, occurs when a woman is forced by her husband to have sex against her will. In the Gambia, as in other places, the wife is considered the property of the husband and is expected to fulfil conjugal rights. Marital rape is rarely reported, and most women do not even perceive it as rape. Among men, discussion of marital rape is taboo. Religion is often cited to justify a man's absolute right to sex with his wife whenever he pleases: according to a study conducted by GAMCOTRAP:

Muslim men do not consider that a husband can be guilty of raping his own wife. According to 
them, Allah has given men the right to approach their wives for sex when and how they wish. They have cited as their authority, the provisions of the verse 223 of Chapter 2 of the Qu'ran which states as follows; 'Your wives are your tilth unto you, so approach your tilth when and how ye will ...' (GAMCOTRAP 2003)

The consequences of a woman refusing sex to her husband can be severe. It can induce domestic violence, or be used as a justification for divorce on the basis that 'aka fang balingna leh' (she is denying me sex). Significantly, it can also be used as a justification for taking another wife. In the face of these penalties, it is understandable that the concept of marital rape is difficult for many women to grasp. Women in our focus group discussions, however, did acknowledge that marital rape is a reality and that they have been battered for refusing sex.

\section{Lesbianism}

In the Gambia, lesbianism is taboo and many people do not believe that it exists. It is not recognised by society and is seen as an unacceptable social relationship. It is referred to as the practice of an alien culture by those who are psychologically and spiritually lost. Lesbian relationships do, however, exist among women in the Gambia, but are kept secret for fear of social rejection. Lesbianism in the Gambia has a historical association with families with powerful women. More research is needed into how far creating alternative social relationships is an expression of resistance within the Gambia's highly patriarchal society, and how far these relationships provide the space for women to express their sexuality and have control over their bodies.

\section{Trafficking in women}

The Gambia is known to engage in this form of abuse at national, regional and international levels. $A$ study undertaken by the Department of Social Welfare and UNICEF found evidence that women are lured with the prospect of well-paid jobs into other countries only to be forced into sex work. The Gambia is an entry point used by a network of actors in the subregion, but little is known about women in the Gambia who have been subjected to trafficking. Stigma makes it difficult for them to share their experience, and little outreach work has been undertaken. Much more work is needed to locate and support these women.

\subsection{Menopause: forced retirement from sex}

The menopause makes many women vulnerable to a further form of abuse of sexual rights: that of sexual and economic neglect on the part of husbands. Many women involved in our field research felt that reaching menopause means retiring from sexual fulfilment, and that this is an injustice. Most women felt that menopause does not affect sexual ability and resented their relegation.

This resentment partly stems from the social and economic consequences of sexual retirement, and partly from continued feelings of unfulfilled sexual desire. Some men use the opportunity of a wife's menopause to look for a younger wife. The taking of a new wife often entails economic and sexual neglect of the first wife. Women understand that their sexuality is closely tied to their status and that sex with their husband is one of the mechanisms through which they guarantee household rights and privileges. The loss of these through a strong association of menopause with sexual retirement is felt acutely.

Our focus group discussions with men regarding sexuality revealed that most elderly men no longer have the ability to sexually satisfy their wives. Most of them expressed their inability to maintain and sustain erection during prolonged sexual intercourse, and felt that they thus lose control over the woman and become powerless. Younger women are seen as a solution to this problem: getting an inexperienced girl can at least mask their sexual inadequacy. Other men felt that getting a younger woman would revitalise their sexual feelings.

For women, on the other hand, the menopause marks a transition to a period in which they can engage in sexual activity without fear of unwanted pregnancy. Hormonal changes that take place during the menopause are normal and may sometimes require having to aid the context within which sexual activity takes place. Gambian women are known to use traditional 'nyefala tedah' ('you'd better be in bed') aphrodisiacs - a local incense prepared to set the tone for romance and sex which is said to arouse both men and women - as well as other methods for stimulating their husbands. Using nyefala tedah is also a method women use to communicate a demand for sex; to claim conjugal rights from husbands. These methods can be and are used by menopausal women to continue to assert their 
sexual and economic status, but many feel that sexual retirement is nevertheless unfairly imposed.

\section{Conclusions}

This article has attempted to locate sexual rights issues in the Gambia's cultural context, drawing attention to various cultural practices which are problematised from the perspectives of women. It has argued that sexuality is powerfully organised by a variety of actors, but excluding women who are not given licence to decide on their sexuality, and that this is the context in which sexual rights are defined and abused.

Cultural expectations, when backed by a conservative religious and political framework, largely outweigh

\section{References}

GAMCOTRAP (2003) 'Gambia Women Law and Customary Practice', mimeo, Banjul: Gambian Committee on Traditional Practices Ilkkaracan, Pinar (2002) 'Women, Sexuality and Social Change in the Middle East and the Maghreb', Social Research, Fall 69.3: 754-79 Imam, Ayesha (2005) Recovering Women's Reproductive Rights: Classical Muslim Scholars Vs the ability of individuals to challenge them. Various cultural practices have been implicated in the abuse of women's sexual rights and condoned by an inadequate or absent legal framework addressing them. Religion is also used to enforce women's sexuality, structuring their vulnerability to sexual rights abuse.

Further research is needed to gather culturally relevant information on the nature and meanings of sexual rights and sexual rights abuse in the Gambia. There is an urgent need for agencies, institutions and individuals to come together in sharing information and work to clarify this fundamental aspect and determinant of human experience.

Contemporary Fundamentalists, Santa Cruz: University of Santa Cruz, California

Morison, L., Scherf, C., Ekpo, G., Paine, K., West, B., Coleman, R. and Walraven, G. (2001) 'The Longterm Reproductive Health Consequences of Female Genital Cutting in Rural Gambia: A Community Based Survey', Tropical Medicine and International Health 6.8: 643-53 